\title{
Carbonatação acelerada efetuada nas primeiras idades em compósitos cimentícios reforçados com polpas celulósicas
}

\author{
Accelerated carbonation in the early ages of cellulose \\ pulps reinforced cement composites
}

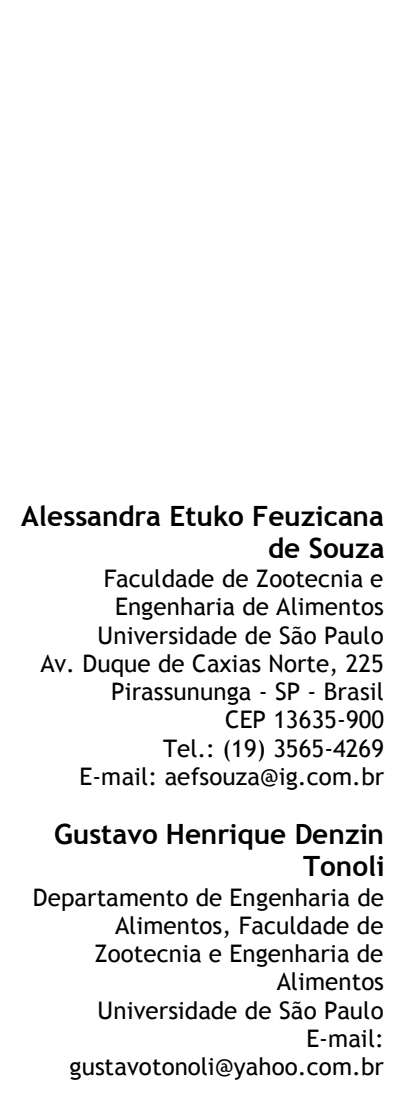

Sergio Francisco dos Santos Departamento de Engenharia de Alimentos, Faculdade de Zootecnia e Engenharia de Alimentos

Universidade de São Paulo E-mail: sfsantos1@usp.br

Holmer Savastano Junior Departamento de Engenharia de Alimentos, Faculdade de Zootecnia e Engenharia de Alimentos

Universidade de São Paulo Tel. (19) 3565-4153 E-mail: holmersj@usp.br

Recebido em 15/04/10 Aceito em 17/08/10

\section{Alessandra Etuko Feuzicana de Souza Almeida Gustavo Henrique Denzin Tonoli Sergio Francisco dos Santos Holmer Savastano Junior}

\section{Resumo}

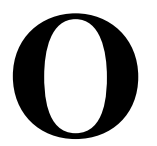

objetivo deste trabalho foi avaliar o efeito carbonatação acelerada nas propriedades físicas e desempenho mecânico de compósitos cimentícios reforçados com altos teores de polpas celulósicas. Os compósitos foram moldados em laboratório pelo processo de suç̧ão a vácuo do excesso de água e posterior prensagem, e a carbonatação acelerada foi realizada em diferentes estágios de cura. $\mathrm{O}$ estudo das propriedades microestruturais foi realizado por microscopia eletrônica de varredura ambiental e difração de raios X. Os resultados obtidos mostraram que a carbonatação acelerada nos primeiros dias de cura resultou em maiores resultados de propriedades mecânicas e melhora na interface fibra-matriz. A carbonatação acelerada reduziu o conteúdo de portlandita $\left[\mathrm{Ca}(\mathrm{OH})_{2}\right]$ e aumentou o teor de calcita $\left[\mathrm{CaCO}_{3}\right]$ que é o principal composto resultante da carbonatação. Consequentemente, ocorreu a redução da alcalinidade na matriz cimentícia, o que pode favorecer a durabilidade das fibras celulósicas que se destacam como alternativas às fibras minerais e sintéticas, e podem contribuir para o desenvolvimento sustentável na tecnologia dos materiais de construção.

Palavras-chave: Fibrocimento. Durabilidade. Polpa de celulose. Carbonatação acelerada.

Abstract

The aim of this study was to evaluate the effect of accelerated carbonation on the physical characteristics and mechanical performance of cement composites reinforced with high-content cellulose pulps. The fiber-cement composites were produced in the laboratory through the slurry dewatering and pressing technique, and accelerated carbonation was applied in different curing stages. The microstructure characteristics were investigated using environmental scanning electron microscopy (ESEM) and X-Ray diffraction. Results showed that the accelerated carbonation in the first days of curing improved the mechanical performance and fiber-matrix interface. The accelerated carbonation decreased the portlandite $\left[\mathrm{Ca}(\mathrm{OH})_{2}\right]$ content and increased the calcite $\left[\mathrm{CaCO}_{3}\right]$ content, which is the main compound produced by the carbonation process. As a result, the alkalinity of the cement matrix decreased, which can favor the durability of the cellulosic fibers that have been recognized as an alternative for mineral and synthetic fibers, and may contribute to the sustainable development in construction materials technology.

Keywords: Fiber-cement. Durability. Cellulosic pulp. Accelerated carbonation. 


\section{Introdução}

A adição de polpas celulósicas derivadas da madeira em compósitos cimentícios tem sido uma prática crescente, por causa das vantagens que elas podem oferecer nas propriedades mecânicas e no processamento dos compósitos, além de ser uma matéria-prima proveniente de fonte renovável, o que contribui para a sustentabilidade na construção civil. Entretanto, essas polpas sofrem degradação em meios altamente alcalinos, encontrados em matriz cimentícia (SAVASTANO JUNIOR; DANTAS; AGOPYAN, 1994).

As fibras vegetais apresentam baixo módulo de elasticidade e alta resistência à tração, proporcionam maior resistência ao impacto, maior absorção de energia, possibilidade de trabalho no estágio pós-fissuração e aumento na capacidade de isolamento termoacústico, quando adequadamente adicionadas às matrizes cimentícias (AGOPYAN; SAVASTANO JUNIOR, 1997, 2000).

Pelo fato de a baixa resistência em meios alcalinos ser característica das polpas celulósicas, aspectos relativos à durabilidade dos produtos fabricados com esse material em compósitos cimentícios ainda devem ser investigados para que esses materiais tenham sua vida útil garantida pelo maior tempo possível, principalmente ao serem expostos às condições climáticas brasileiras.

Caldas e Silva et al. (2009) estudaram a durabilidade de compósitos produzidos com cimento de escória de alto forno reforçados com fibras de celulose por meio de ensaios de envelhecimento natural e acelerado, mas ressaltaram que estudos ainda devem ser realizados para o melhor entendimento do comportamento físico e mecânico desses compósitos.

Resumidamente, a carbonatação pode ser descrita como a difusão do $\mathrm{CO}_{2}$ presente na atmosfera, através dos poros insaturados de matrizes cimentícias. $\mathrm{O} \mathrm{CO}_{2}$ é dissolvido na fase aquosa presente nos poros, transformando-se em ácido carbônico $\left(\mathrm{H}_{2} \mathrm{CO}_{3}\right)$, o qual se dissocia como íons $\mathrm{HCO}_{3}{ }^{-}$e $\mathrm{CO}_{3}{ }^{-}$, juntamente com a dissolução do $\mathrm{Ca}(\mathrm{OH})_{2}$, que libera íons $\mathrm{Ca}^{2+}$ e $\mathrm{OH}^{-}$, os quais precipitam e formam o carbonato de cálcio $\left(\mathrm{CaCO}_{3}\right)$. Um estudo paramétrico e aprofundado sobre a reação do $\mathrm{CO}_{2}$ com cada constituinte do cimento foi realizado por Peter et al. (2008).

A relação entre as alterações do $\mathrm{pH}$ da fase líquida existente nos poros da matriz cimentícia e a instabilidade dos produtos de hidratação conforme o grau de solubilidade foi estudada por diversos autores (GABRISOVA et al., 1991; LAGERBLAD, 2005; TAYLOR, 1997). O $\mathrm{Ca}(\mathrm{OH})_{2}$ é o composto com maior grau de solubilidade e, portanto, o que reage mais rapidamente com o $\mathrm{CO}_{2}$ para a formação do $\mathrm{CaCO}_{3}$ (PADE; GUIMARAES, 2007).

Pode-se encontrar na literatura estudos sobre carbonatação acelerada nas idades iniciais para melhorar a resistência mecânica de compósitos cimentícios, conforme Klem e Berger (1972), para tratamento de resíduos, redução de rejeitos poluentes através da redução da alcalinidade do meio e consequente diminuição da dissolubilidade de elementos químicos nocivos, conforme estudado por Bertos et al. (2004). A carbonatação constitui também um método para acelerar as reações de hidratação dos compostos cimentícios segundo Berger e Klem (1972), que relataram rápido ganho de resistência mecânica dos compostos $\mathrm{C}_{2} \mathrm{~S}$ e $\mathrm{C}_{3} \mathrm{~S}$ (silicatos dicálcico e tricálcico) através do tratamento com $\mathrm{CO}_{2} \log 0$ após a moldagem.

Tonoli et al. (2010a) avaliaram o efeito da carbonatação acelerada aplicada após 28 dias de hidratação na durabilidade de compósitos cimentícios reforçados com polpas Kraft de sisal. Os autores concluíram que esse procedimento melhorou a resistência mecânica dos compósitos após ciclos de envelhecimento acelerado, sendo também observada a redução do teor de hidróxido de cálcio e a densificação da matriz.

São encontrados na literatura diversos trabalhos sobre a durabilidade de compósitos cimentícios com polpas celulósicas utilizando ciclos de carbonatação acelerada como mecanismo de envelhecimento acelerado, além de ciclos de imersão e secagem. Esses trabalhos relatam a melhora das propriedades mecânicas após envelhecimento acelerado utilizando-se a carbonatação, resultante da densificação da matriz e melhora da interface fibra-matriz (AKERS; STUDINKA, 1989; BENTUR; AKERS, 1989; MACVICAR et al.; 1999).

Com base nos trabalhos abordados, a carbonatação mostra-se com potencialidades de melhorar a durabilidade das polpas celulósicas em compósitos cimentícios, pois reduz a alcalinidade da matriz devido à redução do teor de hidróxido de cálcio, resulta em maior quantidade de carbonato de cálcio, que é um composto insolúvel em água e mais denso que o hidróxido de cálcio, além de melhorar as propriedades mecânicas. O rápido ganho de resistência mecânica dos compostos silicatos dicálcico e tricálcico $\left(\mathrm{C}_{2} \mathrm{~S}\right.$ e $\mathrm{C}_{3} \mathrm{~S}$ respectivamente) através do tratamento com $\mathrm{CO}_{2}$ logo após a moldagem sugere que a carbonatação nas idades iniciais melhora as propriedades 
mecânicas de compósitos cimentícios. Tendo-se em vista as vantagens do processo, o objetivo deste trabalho foi avaliar a influência da carbonatação acelerada realizada nos primeiros dias após moldagem dos compósitos, em suas propriedades mecânicas, físicas e microestruturais.

O uso da cura em autoclave para compósitos cimentícios com polpas celulósicas tem sido avaliado em alguns estudos a fim de reduzir o tempo de cura, melhorar a durabilidade e reduzir o consumo de cimento (BENTUR; AKERS, 1989; COUTTS; NI, 1995). Desse modo, o presente trabalho empregou também a cura em autoclave para os compósitos em estudo com base nos trabalhos citados, além da cura imersa em água para a comparação entre as metodologias, sendo essas empregadas em trabalhos recentes, com bons resultados (TONOLI et al., 2010b).

\section{Estudo experimental}

\section{Matérias-primas}

Foram empregados os seguintes materiais e respectivas proporções em massa seca: 10\% (em relação à massa de cimento) de polpa celulósica não branqueada de eucalipto, 77,2\% de CP V-ARI (ABNT, 1983) e 12,8\% de calcário agrícola moído. O calcário foi usado como substituição parcial do cimento Portland com o objetivo de reduzir custos com a formulação da mistura, como normalmente empregado na indústria de fibrocimento (BEZERRA et al., 2006). As massas específicas do cimento e calcário são $3,10 \mathrm{~g} / \mathrm{cm}^{3}$ e $2,8 \mathrm{~g} / \mathrm{cm}^{3}$ respectivamente. Suas composições químicas (\% em massa de óxidos) foram determinadas por espectrometria de fluorescência de raios $\mathrm{X}$ e estão apresentadas na Tabela 1.

As distribuições de diâmetro equivalente de partículas do cimento e do calcário foram determinadas em um equipamento Malvern Mastersizer S long bed, versão 2.19, e estão apresentadas na Figura 1.

\begin{tabular}{|c|c|c|c|c|c|c|c|c|c|c|c|}
\hline & $\mathrm{CaO}$ & MgO & $\mathrm{SiO}_{2}$ & $\mathrm{Al}_{2} \mathrm{O}_{3}$ & $\mathrm{Fe}_{2} \mathrm{O}_{3}$ & $\mathrm{Na}_{2} \mathrm{O}$ & $\mathrm{K}_{2} \mathrm{O}$ & $\mathrm{SO}_{3}$ & MnO & $\mathbf{P}_{2} \mathbf{O}_{5}$ & $\mathrm{TiO}_{2}$ \\
\hline & \multicolumn{11}{|c|}{$(\%$ em massa $)$} \\
\hline Cimento $^{1}$ & 63,5 & 3,1 & 19,4 & 4,1 & 2,3 & 0,2 & 1,1 & 3,0 & - & - & - \\
\hline Calcário $^{2}$ & 39,1 & 8,9 & 9,0 & 2,2 & 1,2 & 0,1 & 0,4 & - & $<0,1$ & 0,2 & 0,1 \\
\hline
\end{tabular}

Obs.: ${ }^{1}$ Cimento Portland comum CPV-ARI (ABNT, 1983), perda ao fogo (PF) a $1.000{ }^{\circ} \mathrm{C}=3,3 \%$ em massa; ${ }^{2}$ calcário, perda ao fogo (PF) a $1.000{ }^{\circ} \mathrm{C}=39,0 \%$ em massa.

Tabela 1 - Composição química (\% em massa de óxidos) do cimento e do calcário

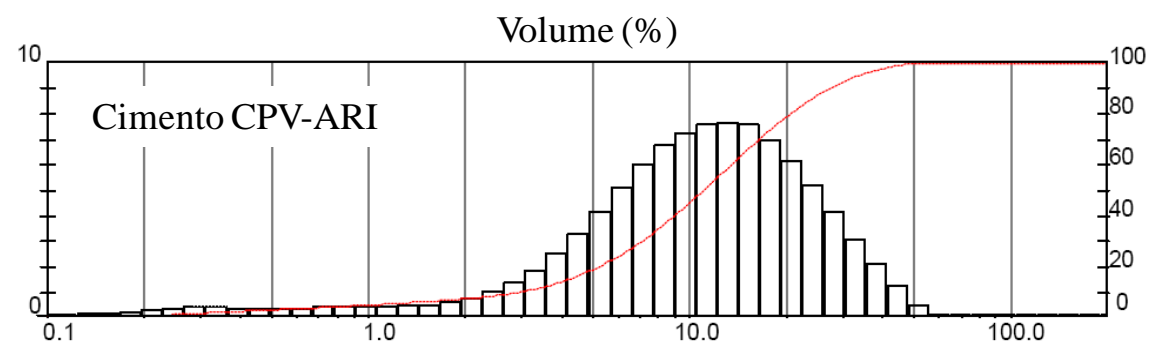

Diâmetro da partícula $(\mu \mathrm{m})$

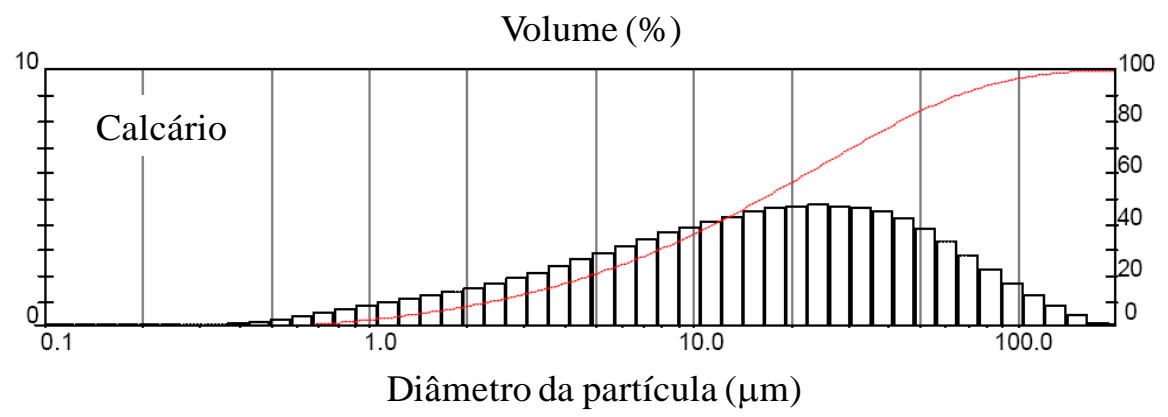

Figura 1- Distribuição de diâmetro equivalente de partículas do cimento Portland (CPV-ARI) e do calcário 


\section{Metodologia de moldagem e cura}

Placas de fibrocimento com dimensões nominais de $200 \mathrm{~mm}$ x $200 \mathrm{~mm}$ x $5 \mathrm{~mm}$ foram preparadas em laboratório por sucção do excesso de água e posterior prensagem (SAVASTANO JUNIOR et al., 2000). As formulações foram ajustadas de acordo com estudos prévios (TONOLI et al., 2009; TONOLI et al., 2010b), que também empregaram os teores em massa seca iguais a 77,2\% de cimento Portland (CP II E 32), 12,8\% de calcário agrícola moído e $10 \%$ de polpas celulósicas.

A carbonatação acelerada foi realizada em câmara climática mediante aplicação de 18 ciclos de $\mathrm{CO}_{2}$ com duração de 3 min para cada ciclo a uma vazão aproximada de $43 \mathrm{~m}^{3} / \mathrm{h}$ (obtendo-se a saturação do interior da câmara com o gás), com temperatura e umidade controladas $\left(60^{\circ} \mathrm{C}\right.$ e $90 \%$ UR) e duração aproximada de 3 dias. A carbonatação foi avaliada pela titulação com solução de fenolftaleína a $2 \%$, usualmente empregada para indicação do pH. Essa solução de fenolftaleína é aplicada às superfícies dos materiais e apresenta coloração violeta (ou roxa) quando em contato com compostos altamente básicos ( $\mathrm{pH}$ entre 10 e 12), como os produtos de hidratação alcalinos do cimento, e incolor quando o $\mathrm{pH}$ é ácido, indicando a ocorrência do processo de carbonatação. Desse modo, a carbonatação foi avaliada visualmente pela alteração da cor na superfície do compósito quando em contato com a solução indicadora de $\mathrm{pH}$.

As diferentes condições de cura foram adotadas com base em trabalhos da literatura e são descritas abaixo, além de esquematizadas na Figura 2.
$\mathrm{T}_{0}$ : cura úmida. Os corpos de prova foram mantidos em câmara climática com temperatura e umidade relativa controladas $\left(60{ }^{\circ} \mathrm{C}\right.$ e $90 \%$ respectivamente) por 2 dias. Após essa etapa, os corpos de prova foram mantidos em cura saturada ao ar a $25^{\circ} \mathrm{C}$.

$\mathrm{T}_{1}$ : autoclave. Os corpos de prova foram mantidos em câmara climática com temperatura e umidade relativa controladas $\left(60{ }^{\circ} \mathrm{C}\right.$ e $90 \%$ respectivamente $)$ por $24 \mathrm{~h}$. Na sequência, os corpos de prova foram curados aceleradamente em autoclave por $10 \mathrm{~h}$, à temperatura de $140{ }^{\circ} \mathrm{C}$ e pressão em torno de 0,55 MPa. Em seguida, prosseguiu-se com os ciclos de carbonatação acelerada em câmara climática, conforme descrito anteriormente. Após a carbonatação, os corpos de prova foram mantidos sob cura saturada ao ar a $25{ }^{\circ} \mathrm{C}$ até completar 28 dias.

$\mathrm{T}_{2}$ : carbonatação aos três dias. Os corpos de prova foram mantidos em câmara climática com temperatura e umidade relativa controladas $\left(60{ }^{\circ} \mathrm{C}\right.$ e $90 \%$ respectivamente) por 2 dias, prosseguindo com a aplicação dos ciclos de $\mathrm{CO}_{2}$ para a obtenção da carbonatação acelerada da matriz cimentícia. Após a carbonatação, os corpos de prova foram mantidos sob cura saturada ao ar a $25{ }^{\circ} \mathrm{C}$ até completar 28 dias.

$\mathrm{T}_{3}$ : carbonatação aos 27 dias. Os corpos de prova foram mantidos em câmara climática com temperatura e umidade relativa controladas $\left(60{ }^{\circ} \mathrm{C}\right.$ e $90 \%$ respectivamente) por 2 dias. Após essa etapa, os corpos de prova foram mantidos sob cura saturada em água por 26 dias, prosseguindo-se com a aplicação dos ciclos de carbonatação acelerada.
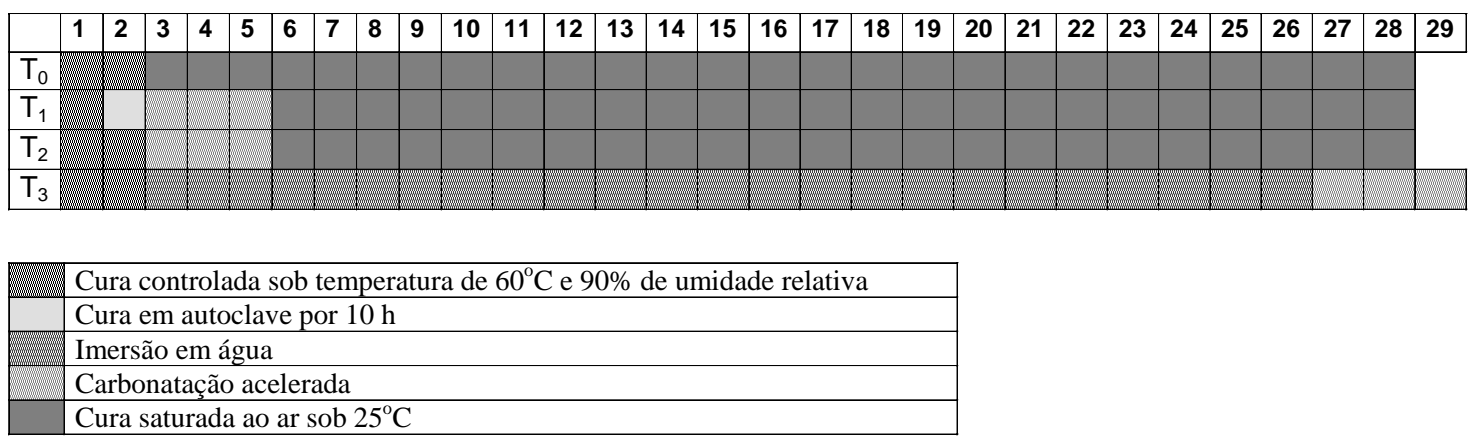

Figura 2 - Cronograma representativo para cada condição de cura em relação aos dias: $T_{0}$ (cura úmida), $\mathrm{T}_{1}$ (autoclave), $\mathrm{T}_{2}$ (carbonatação aos 3 dias) e $\mathrm{T}_{3}$ (carbonatação aos 27 dias) 


\section{Ensaios mecânicos e físicos dos compósitos}

As placas com espessura aproximada de $5 \mathrm{~mm}$ foram cortadas em 4 corpos de prova $(165 \mathrm{~mm} \mathrm{x}$ $40 \mathrm{~mm} \times 5 \mathrm{~mm}$ ) com disco diamantado refrigerado com água, para a realização de ensaios mecânicos e físicos. Os testes mecânicos foram realizados em máquina universal de ensaios Emic modelo DL30000 , equipada com célula de carga de $1 \mathrm{kN}$. A configuração de flexão a quatro pontos (distância entre apoios inferiores igual a $135 \mathrm{~mm}$ e distância entre apoios superiores igual a $45 \mathrm{~mm}$ ) foi empregada para a determinação dos valores de módulo de ruptura (MOR), limite de proporcionalidade (LOP), módulo elástico (MOE) e energia específica (EE) do compósito. Os procedimentos adotados para os ensaios foram baseados no procedimento experimental RILEM (1984) e no trabalho de Savastano Junior (2000), para cálculo da energia específica.

$$
\begin{aligned}
& L O P=\frac{P_{l o p} \cdot L_{v}}{b \cdot h^{2}} \\
& M O R=\frac{P_{\max } \cdot L_{v}}{b \cdot h^{2}} \\
& M O E=\frac{276 \cdot L_{v}^{3}}{1296 \cdot b \cdot h^{3}} \cdot(m)
\end{aligned}
$$

Onde:

$\mathrm{P}_{\text {lop }}$ é a carga máxima em regime elástico;

$\mathrm{P}_{\max }$ é a carga máxima atingida;

$\mathrm{L}_{\mathrm{v}}$ é a medida do maior vão de ensaio (135 mm); b e h são a largura e a espessura dos compósitos respectivamente; e

m é a tangente do ângulo de inclinação da curva carga $v s$ flecha, dentro do regime elástico.

A energia específica (EE) foi definida como a energia absorvida durante o teste de flexão, dividida pela área da secção transversal da amostra (Eq. 4), como descrito previamente (TONOLI et al., 2007) e adaptado de RILEM (1984). A energia absorvida foi obtida pela integral da área sob a curva carga $v s$ flecha até o ponto correspondente a $30 \%$ da carga máxima atingida (correspondente à tensão de $0,3 *$ MOR). A flecha durante o teste de flexão foi coletada por um deflectômetro com precisão de $0,001 \mathrm{~mm}$ posicionado no meio do vão, na face inferior do compósito. Os valores de tensão $(\sigma)$ foram calculados com a Eq. 2 para cada valor de carga, P. Os valores de flecha foram divididos pela medida do vão $(135 \mathrm{~mm}) \mathrm{e}$ chamados no presente trabalho de flecha específica. A Figura 3 esquematiza uma curva típica de tensão vs flecha específica do compósito cimentício e as propriedades mecânicas LOP, MOR e energia absorvida, avaliadas no presente trabalho. Os valores de MOE foram determinados pela Eq. 3, usando as curvas carga $v s$ flecha.

$$
E E=\frac{\text { energia absorvida }}{b \cdot h}
$$

Eq. 4

Os valores de densidade aparente (DA) e porosidade aparente (PA) dos compósitos foram obtidos após 28 dias, conforme os procedimentos da norma ASTM C 948 (1981).

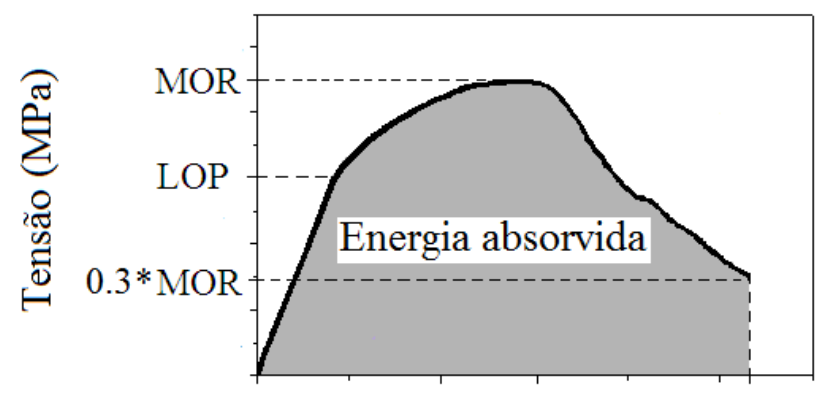

Flecha específica $(\mathrm{mm} / \mathrm{mm})$

Figura 3 - Esquema de uma curva típica de tensão vs flecha específica do compósito cimentício e a representação dos parâmetros mecânicos 


\section{Análise por microscopia eletrônica de varredura}

O efeito das diferentes condições de cura na microestrutura dos compósitos foi avaliado por microscopia eletrônica de varredura ambiental (MEVA), com equipamento marca FEI Quanta 600 FEG (Field Emission Gun) e sistemas de microanálise Quantax (Bruker), utilizando-se detector GAD (detector analítico gasoso) em superfícies polidas de secções transversais dos compósitos. As imagens obtidas permitem a identificação de fases cimentícias pelo contraste entre números atômicos. Áreas escuras e claras estão relacionadas aos elementos leves e pesados respectivamente. Os procedimentos para preparação das amostras são descritos por Savastano Junior et al. (2005). A identificação dos elementos químicos na secção transversal dos compósitos foi realizada por meio de espectroscopia de energia dispersiva (EDS) nas mesmas amostras com superfície polida. Também foram analisadas as superfícies de fratura após os ensaios mecânicos dos compósitos em estudo, através de microscopia eletrônica de varredura com detector de elétrons secundários (SE).

\section{Análise por difração de raios $X$}

As fases cimentícias foram identificadas por difração de raios X (DRX) em um equipamento Rigaku Rotoflex RU-200B com goniômetro horizontal, câmara multifuncional e monocromador. As condições de operação foram: $50 \mathrm{kV}$ de voltagem, $100 \mathrm{~mA}$ de corrente elétrica, velocidade de $1 \%$ min e passo de $0,02^{\circ}$. Após os ensaios mecânicos, as amostras foram imersas em etanol por $10 \mathrm{~h}$ e secas em estufa sob $60{ }^{\circ} \mathrm{C}$ por 24 h, conforme realizado por Mohr et al. (2007). As amostras usadas nesta análise foram moídas (aproximadamente com 50 dias), passadas por uma peneira de 325 mesh $(0,045 \mathrm{~mm})$, e armazenadas em embalagens seladas até o momento de realização do ensaio. A identificação das fases cristalinas é realizada por meio de listagens contendo os ângulos de Bragg, a distância interplanar, as respectivas intensidades dos picos e ainda as intensidades relativas de vários compostos identificados pela base de dados "International Centre for Difraction Data" (ICDD). Essa técnica foi utilizada para a identificação dos compostos cristalinos formados nos compósitos.

\section{Resultados e discussão}

\section{Propriedades mecânicas e físicas}

As propriedades mecânicas foram obtidas após completar todas as etapas descritas anteriormente sobre os procedimentos de cura $\left(\mathrm{T}_{0}, \mathrm{~T}_{1}, \mathrm{~T}_{2}, \mathrm{~T}_{3}\right)$. A Figura 4 apresenta as curvas típicas tensão vs flecha específica para cada condição de cura. Os compósitos submetidos à condição de cura com carbonatação acelerada (vide Figura 2) apresentaram maior valor de MOR, de MOE e de LOP (Figuras 5 e 6) em relação aos compósitos não carbonatados. Observa-se que, entre os compósitos carbonatados, aqueles submetidos à condição de cura $\mathrm{T}_{2}$ (carbonatação acelerada aos três dias de idade) têm o melhor desempenho mecânico, principalmente quanto ao MOR. É importante destacar que o MOR indica a participação conjunta da matriz e das fibras, ou seja, essa propriedade mecânica está relacionada com a resistência mecânica da matriz e os mecanismos de tenacificação entre as fibras e a matriz (BENTUR; MINDESS, 2007). Os valores de LOP foram próximos para as amostras carbonatadas, quando considerados os desvios padrão, sugerindo que o comportamento mecânico desses compósitos é semelhante antes do início da fissuração (regime elástico da curva tensãodeformação observado na Figura 4).

Os compósitos submetidos à condição de cura $\mathrm{T}_{0}$ (não carbonatados) apresentaram os menores valores de MOR, MOE e LOP, mas apresentaram o maior valor de energia específica, além de apresentar maior flecha específica $(0,04 \mathrm{~mm} / \mathrm{mm})$ (Figura 4), o que mostra a maior capacidade de deformação do compósito.

A energia específica está relacionada com os mecanismos de tenacificação associados às fibras, os quais atuam no processo de fratura do compósito, tais como desprendimento (debond), arrancamento (pull-out), pontes (bridging) e fratura de fibras. A Figura $5 \mathrm{~b}$ mostra que os compósitos não carbonatados apresentam valores de energia específica superiores aos dos compósitos carbonatados submetidos às condições de cura $\mathrm{T}_{1}$ (autoclave) e $\mathrm{T}_{3}$ (carbonatação aos 27 dias), e próximos aos da condição $\mathrm{T}_{2}$ (carbonatação no terceiro dia após moldagem), considerando-se os desvios padrão. Esse resultado indica que a aplicação da carbonatação acelerada após os 2 primeiros dias de cura minimizou a degradação da interface entre fibra e matriz, demonstrando ser mais vantajosa do que a carbonatação após a cura, seja por meio de autoclave (condição $\mathrm{T}_{1}$ ) ou saturada em água (condição $\mathrm{T}_{3}$ ). 


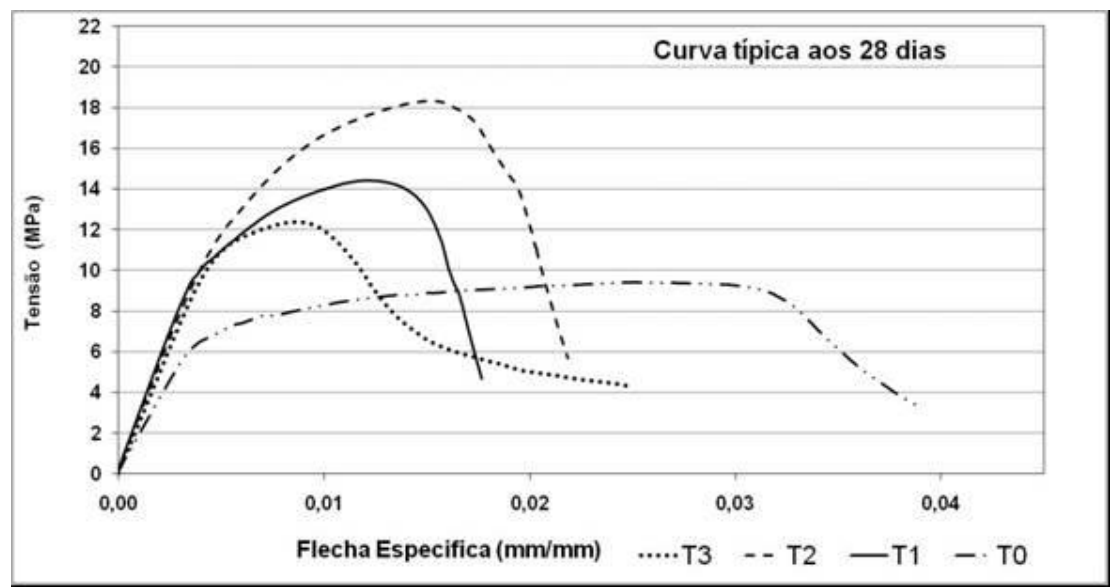

Legenda:

$\mathrm{T}_{0}$ : cura úmida;

$\mathrm{T}_{1}$ : carbonatação após cura em autoclave;

$\mathrm{T}_{2}$ : carbonatação aos 3 dias; e

$\mathrm{T}_{3}$ : carbonatação aos 27 dias após cura imersa em água.

Figura 4 - Curvas típicas de tensão vs flecha específica obtidas de ensaios de flexão a quatro pontos em compósitos submetidos a diferentes condições de cura, aos 28 dias

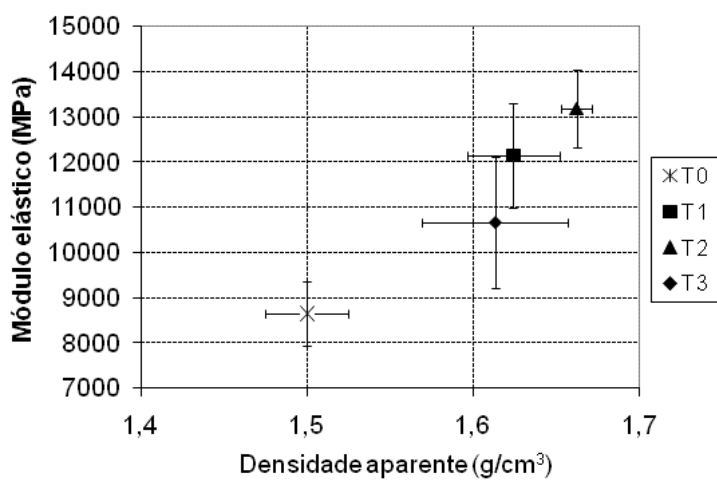

(a)

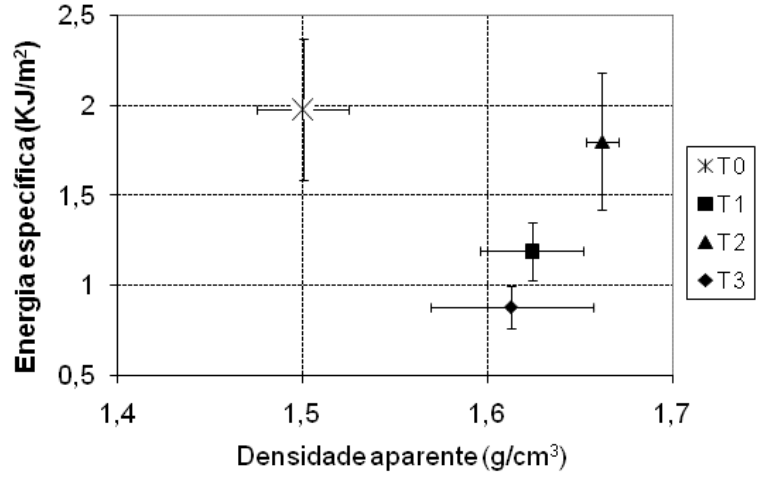

(b)

Legenda:

$\mathrm{T}_{0}$ : cura úmida;

$\mathrm{T}_{1}$ : arbonatação após cura em autoclave;

$\mathrm{T}_{2}$ : carbonatação aos 3 dias; e

$\mathrm{T}_{3}$ : carbonatação aos 27 dias após cura imersa em água.

Figura 5 - Valores médios de (a) módulo de elasticidade (MOE) em função da densidade aparente (DA), e (b) energia específica (EE) em função da densidade aparente (DA) dos compósitos de fibrocimento após diferentes condições de cura

O compósito submetido à condição de cura $T_{2}$ (carbonatação aos 3 dias) apresentou maior valor de densidade aparente (Figura 5) e menor porosidade aparente (Figura 6) entre os compósitos, contrariamente ao compósito não carbonatado, que apresentou menor densidade aparente e maior porosidade aparente. As amostras carbonatadas apresentaram valores de densidade aparente próximos, possivelmente devido à maior presença de carbonato de cálcio, que é mais denso que o hidróxido de cálcio. $\mathrm{O}$ maior valor de porosidade aparente para a condição $\mathrm{T}_{3}$ (Figura 6) sugere que a cura imersa em água aumenta a porosidade e que a carbonatação após 27 dias de imersão não diminuiu essa porosidade, o que justifica os menores valores de propriedades mecânicas para essa condição de cura, comparando-se com as outras amostras carbonatadas. A maior densidade aparente e a menor porosidade aparente estão relacionadas com uma matriz com menor quantidade de defeitos e mais compacta. Esses resultados estão de acordo com aqueles observados nas propriedades mecânicas dos compósitos carbonatados (Figuras 5 e 6), com o destaque para a condição de cura $T_{2}$, que apresentou maiores valores de propriedades mecânicas entre todos os compósitos avaliados. 

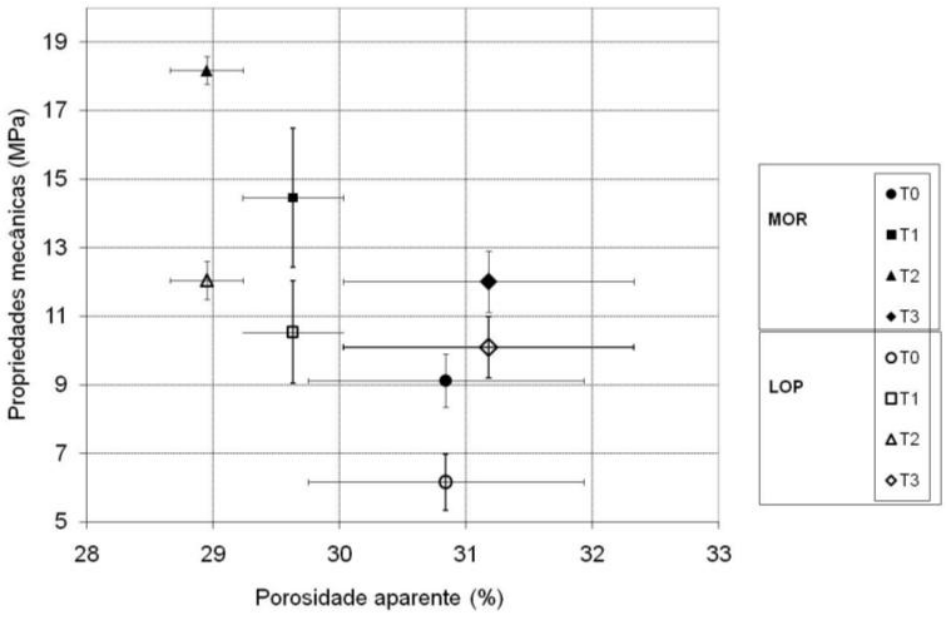

Legenda:

$\mathrm{T}_{0}$ : cura úmida;

$\mathrm{T}_{1}$ : carbonatação após cura em autoclave;

$\mathrm{T}_{2}$ : carbonatação aos 3 dias; e

$\mathrm{T}_{3}$ : carbonatação aos 27 dias após cura imersa em água.

Figura 6 - Valores médios de módulo de ruptura (MOR) em função da porosidade aparente (PA) e limite de proporcionalidade (LOP) em função da porosidade aparente (PA) dos compósitos de fibrocimento após diferentes condições de cura

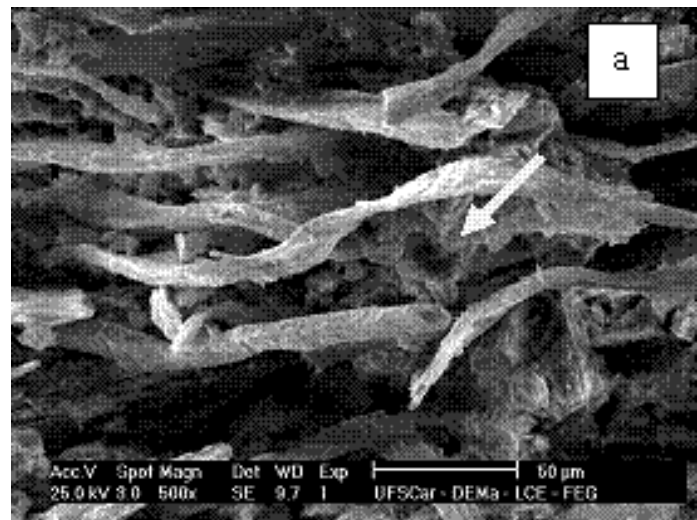

(a) compósito submetido à condição de cura $T_{0}$, não carbonatado

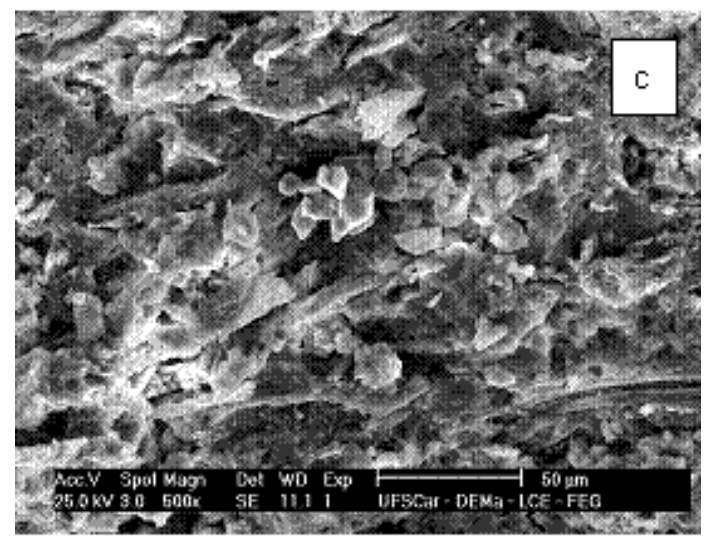

(c) condição de cura T2, carbonatado após 2 dias de cura em câmara climática

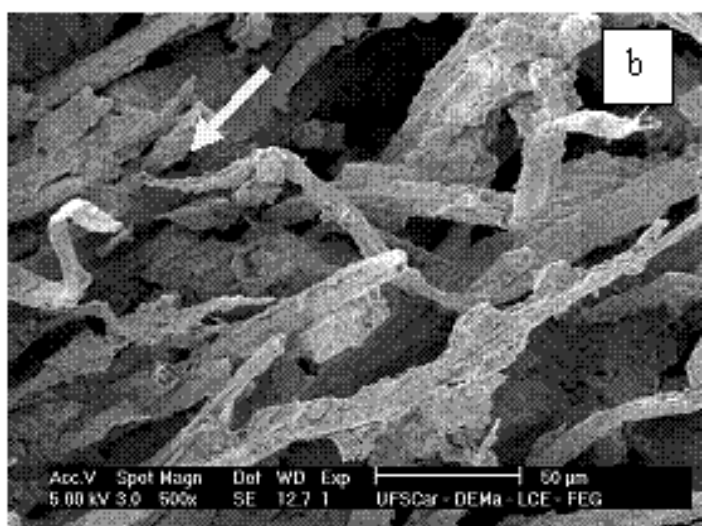

(b) condição de cura, T1, carbonatado após a cura em autoclave

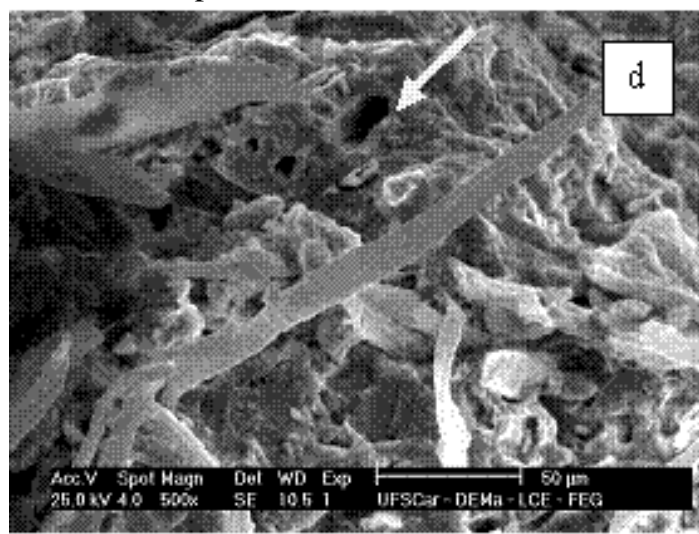

(d) condição de cura T3, carbonatado após cura saturada em água

Figura 7 - Micrografias obtidas por microscopia eletrônica de varredura com uso de detector de elétrons secundários (SE) da superfície de fratura dos corpos de prova após ensaios mecânicos 


\section{Microscopia eletrônica de varredura}

As imagens mostradas na Figura 7 foram obtidas por microscopia eletrônica de varredura das superfícies de fratura depois de realizados os ensaios mecânicos para os corpos de prova em estudo. A análise dessas micrografias permite fazer considerações sobre a interação entre fibra e matriz cimentícia. Os corpos de prova carbonatados após 2 dias de cura em câmara com condições controladas $\left(\mathrm{T}_{2}\right)$ não apresentaram fibras arrancadas (Figura 7c), podendo-se observar a matriz cimentícia densa e compacta, o que possivelmente favoreceu a melhor aderência entre fibra e matriz e incrementou a resistência mecânica, conforme já mencionado. As outras amostras apresentaram considerável quantidade de fibras arrancadas da matriz, indicando baixa aderência.

As micrografias apresentadas nas Figuras 8 e 9 foram obtidas por microscopia eletrônica de varredura de amostras polidas de corpos de prova submetidos às condições $T_{0}$ e $T_{2}$ respectivamente, ou seja, corpos de prova não carbonatados e carbonatados após 2 dias de cura em condições controladas na câmara climática. Os resultados obtidos nas análises por espectroscopia de energia dispersiva podem ser observados nas Tabelas 2 e 3 para cada ponto indicado nas respectivas micrografias.

A análise das imagens de amostras polidas mostra as fases cimentícias formadas após os mecanismos de hidratação para cada procedimento de cura. Os vazios preenchidos com resina estão relacionados com as tonalidades mais escuras que não apresentam a forma arredondada ou elíptica típica das fibras celulósicas. Conforme a Tabela 2, referente à Figura 8, observa-se nos pontos 1, 2 e 3 os produtos de hidratação $\left(\mathrm{Ca}(\mathrm{OH})_{2}, \mathrm{CaO} \cdot \mathrm{SiO}_{2} \mathrm{e}\right.$ $\mathrm{CaO} . \mathrm{Al}_{2} \mathrm{O}_{3}$ ), com o ponto 2 apresentando alto teor de silício ( $\mathrm{Si}$ ) e com tonalidade clara, sugerindo ser um grão anidro. Os pontos 4 e 5 de tonalidade mais escura apresentam maiores teores de carbono (C), tipicamente encontrados nas fibras celulósicas.

A micrografia da Figura 9 corresponde ao corpo de prova carbonatado na condição $T_{2}$ e evidencia microestrutura mais compacta que a apresentada na Figura 8 (amostra não carbonatada), com menores quantidades de vazios representados pela tonalidade mais escura (preenchimento com resina). Conforme a Tabela 3 , os pontos 1 a 3 correspondem aos produtos de hidratação do cimento $\left(\mathrm{Ca}(\mathrm{OH})_{2} ; \mathrm{CaO} \cdot \mathrm{SiO}_{2} ; \mathrm{CaO} \cdot \mathrm{Al}_{2} \mathrm{O}_{3} ; \mathrm{CaCO}_{3}\right)$. Os espectros dos pontos 4, 5 e 6 com altos teores de carbono são típicos de polpas celulósicas.

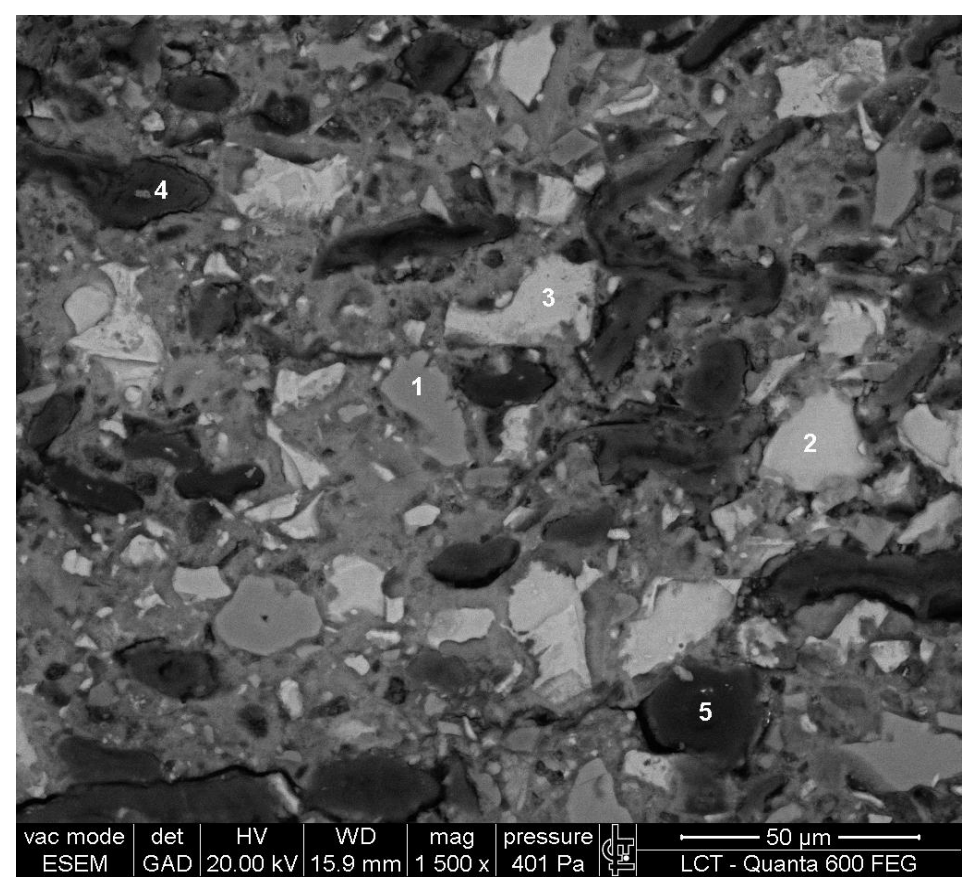

Figura 8 - Micrografia obtida por microscopia eletrônica de varredura ambiental de amostra não carbonatada $\left(T_{0}\right)$ polida, utilizando-se detector de elétrons GAD 


\begin{tabular}{c|c|c|c|c}
\hline \multirow{2}{*}{ Ponto } & \multicolumn{4}{|c}{ Elemento químico } \\
\cline { 2 - 5 } & C & O & Si & Ca \\
\hline 1 & 23 & 35 & 17 & 105 \\
\hline 2 & 18 & 32 & 42 & 122 \\
\hline 3 & 18 & 32 & 25 & 104 \\
\hline 4 & 29 & 30 & 18 & 62 \\
\hline 5 & 44 & 31 & 17 & 76 \\
\hline
\end{tabular}

Tabela 2 - Intensidade (cps/eV) dos picos obtidos por espectroscopia de energia dispersiva de raios $\mathrm{X}$ (EDS) associada à microscopia eletrônica de varredura, para os pontos 1 a 5 indicados na Figura 8

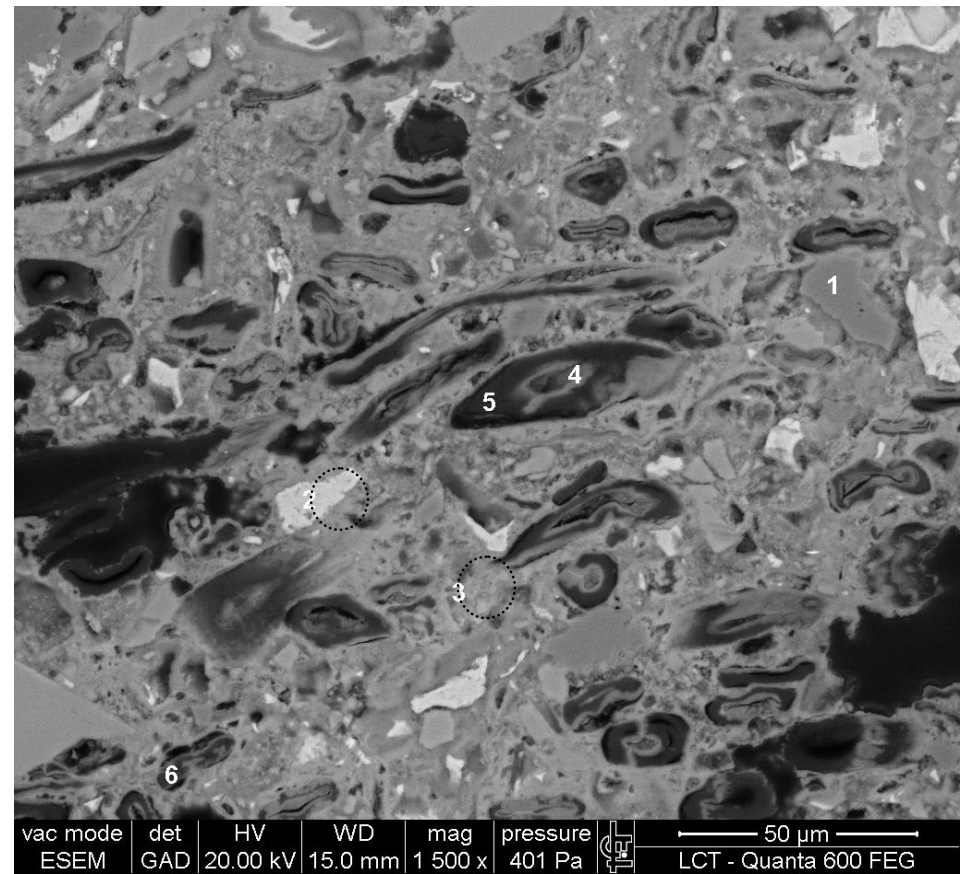

Figura 9 - Micrografia obtida por microscopia eletrônica de varredura ambiental de amostra polida de corpo de prova submetido às condições $T_{2}$, utilizando-se detector de elétrons GAD

\begin{tabular}{c|c|c|c|c}
\hline \multirow{2}{*}{ Ponto } & \multicolumn{4}{|c}{ Elemento químico } \\
\cline { 2 - 5 } & C & O & Si & Ca \\
\hline 1 & 23 & 42 & 12 & 77 \\
\hline 2 & 22 & 32 & 15 & 96 \\
\hline 3 & 21 & 37 & 28 & 92 \\
\hline 4 & 45 & 37 & 12 & 77 \\
\hline 5 & 47 & 26 & 12 & 65 \\
\hline 6 & 40 & 25 & 14 & 64 \\
\hline
\end{tabular}

Tabela 3 - Intensidade (cps/eV) dos picos obtidos por espectroscopia de energia dispersiva de raios $\mathrm{X}$ (EDS) associada à microscopia eletrônica de varredura, para os pontos 1 a 6 indicados na Figura 9

As micrografias da Figura 10 mostram a falta de aderência entre fibra e matriz para a amostra não carbonatada da condição $\mathrm{T}_{0}$ (Figura 10a) e a melhora dessa interface na amostra carbonatada sob condição $\mathrm{T}_{2}$ (Figura 10b). Essa é a explicação para os maiores valores de energia específica para os compósitos da condição $\mathrm{T}_{0}$ (não carbonatados) em relação à condição $\mathrm{T}_{2}$ (carbonatados). Uma melhor interface entre fibra e matriz promove a ruptura da fibra em vez de seu arrancamento. O arrancamento das fibras contribui para a absorção de energia com a fricção, enquanto a ruptura das fibras contribui para maiores valores de resistência do compósito (SAVASTANO JUNIOR et al. 2003, 2005). O baixo valor do MOR para a amostra não carbonatada pode ser justificado pela baixa aderência entre fibra e matriz, pois essa propriedade está relacionada com a participação conjunta entre a matriz e as fibras. 


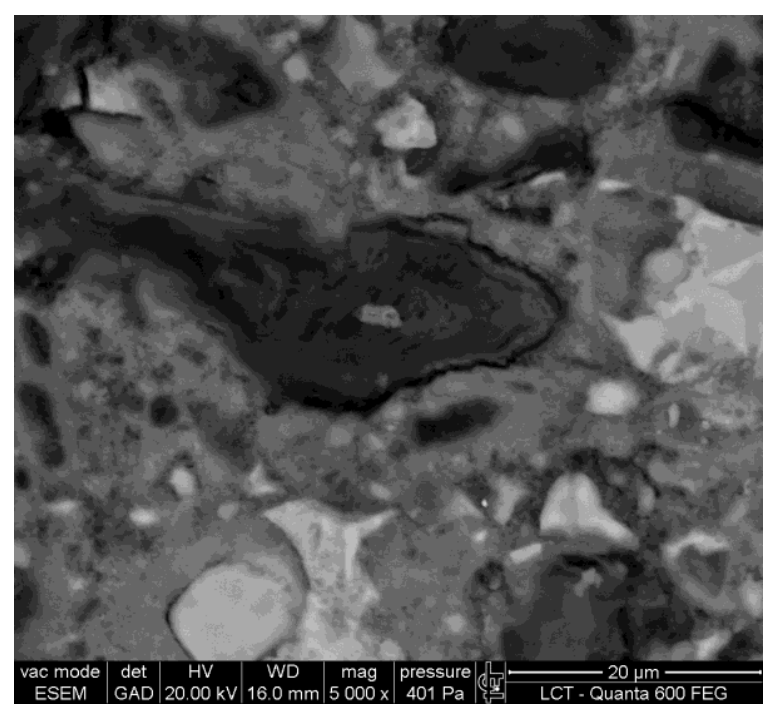

(a) Micrografias de amostra não carbonatada evidenciando perda de aderência entre fibra e matriz cimentícia

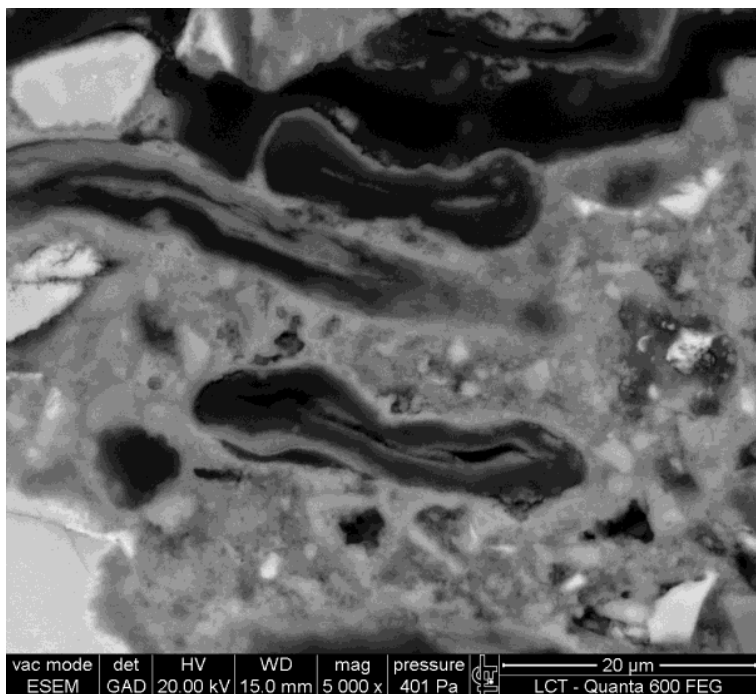

(b) Imagem de amostra carbonatada (condição $\mathrm{T}_{2}$ ) observando-se a boa aderência entre fibra e matriz

Figura 10 - Micrografias obtidas por microscopia eletrônica de varredura ambiental de seções polidas de corpos de prova após ensaios mecânicos, utilizando-se detector de elétrons GAD

\begin{tabular}{l|l}
\hline & \multicolumn{2}{c}{ Condição hidratada } \\
\hline P & Portlandita \\
\hline S & Silicato anidro \\
\hline C & Calcita \\
\hline E & Etringita \\
\hline C-S-H & Gel de C-S-H representado pelo halo amorfo entre $28^{\circ}$ e $34^{\circ} 2 \theta$ \\
\hline
\end{tabular}

Tabela 4 - Identificação das fases presentes em compósitos cimentícios hidratados

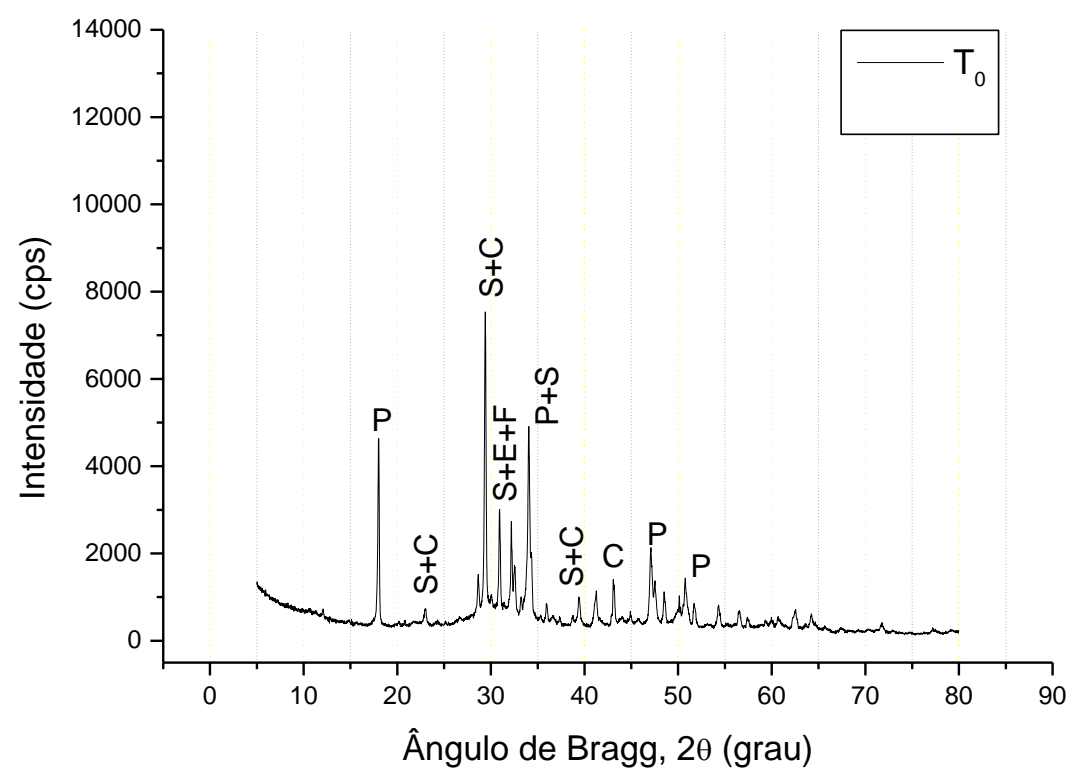

Figura 11 - Difratograma de amostra sob a condição de cura $\mathrm{T}_{0}$ (cura úmida)

\section{Difração de raios $\mathrm{X}$}

A técnica de difração de raios $X$ possibilita identificar as fases cristalinas descritas na Tabela
4, formadas no mecanismo de hidratação para cada condição de cura. Essas fases são representadas nos difratogramas das Figuras 11 a 14. 


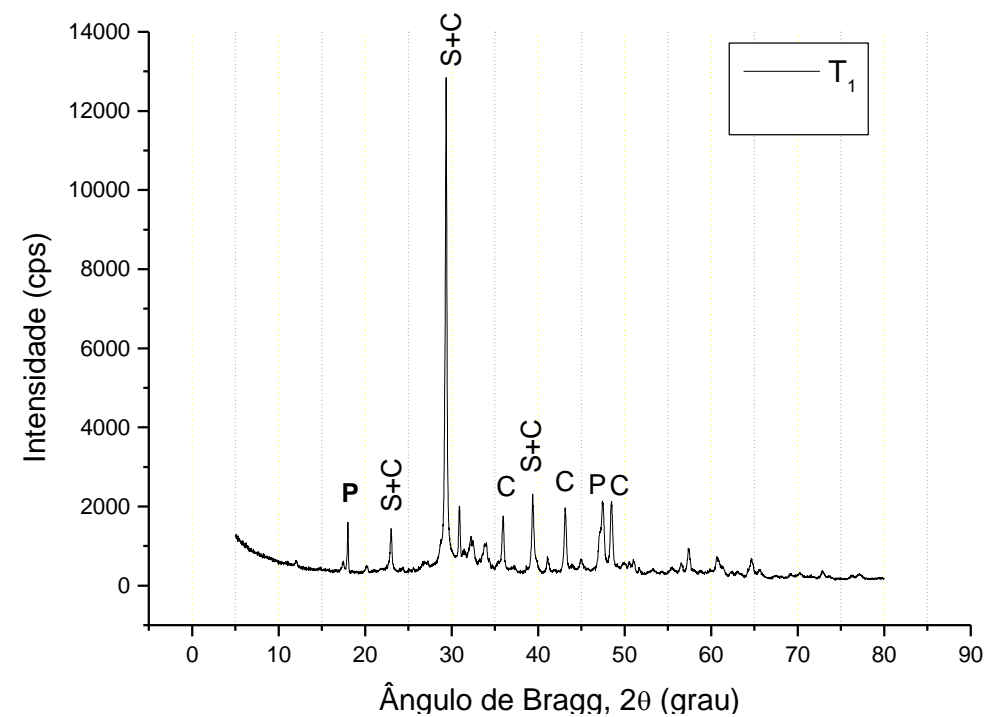

Figura 12 - Difratograma de amostra sob a condição de cura $\mathrm{T}_{1}$ (autoclave)

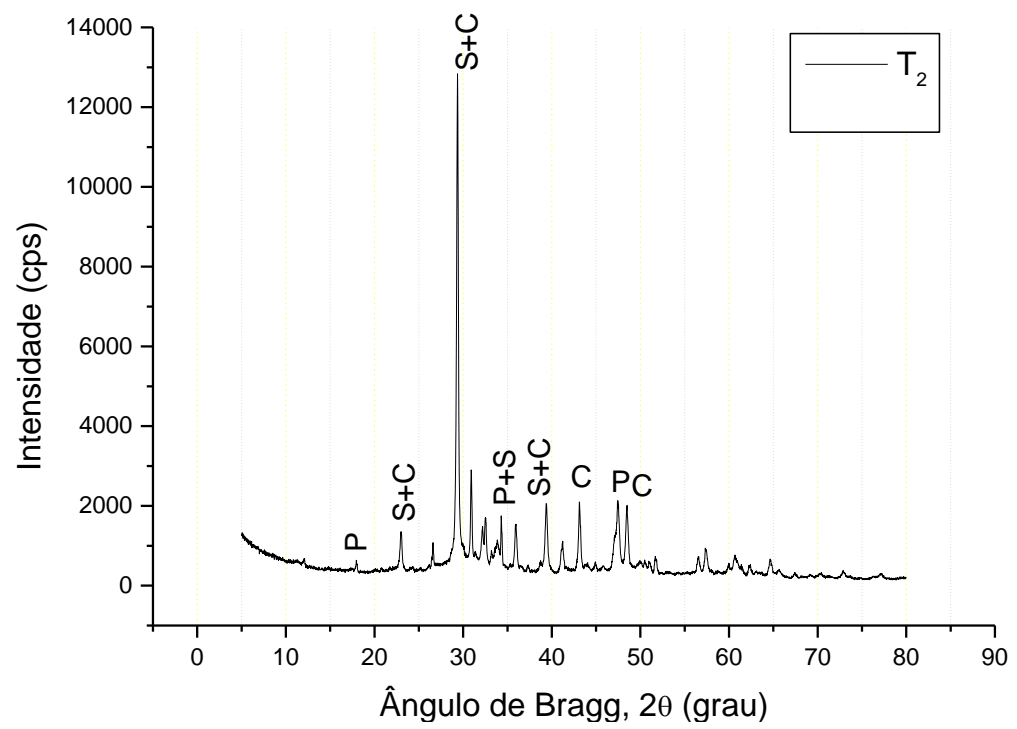

Figura 13 - Difratograma de amostra sob a condição de cura $T_{2}$ (carbonatação aos 3 dias)

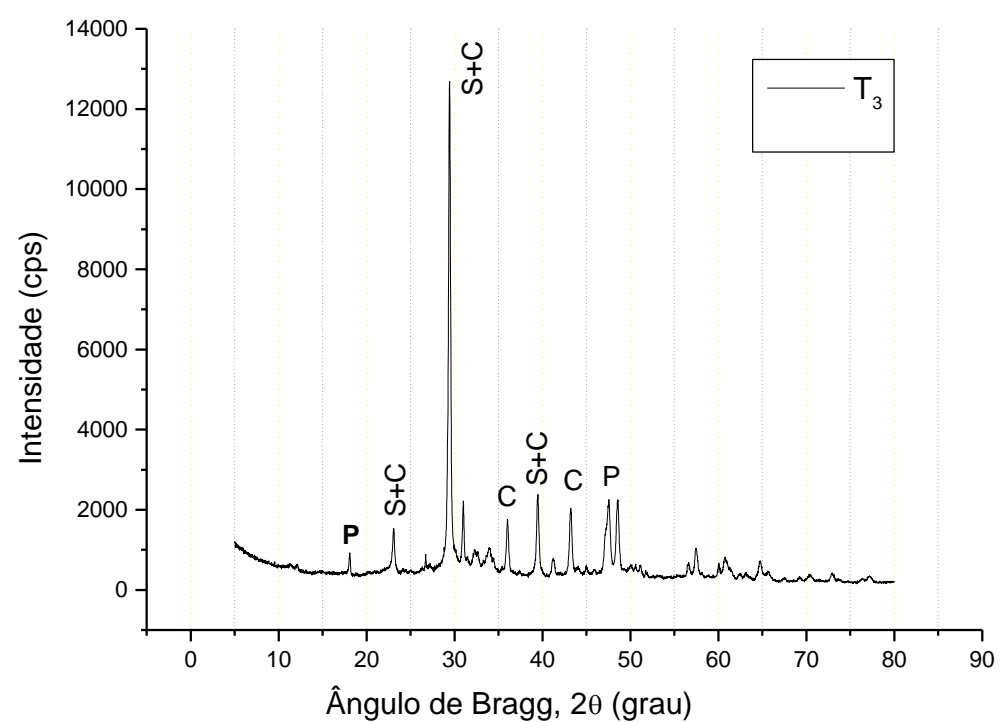

Figura 14 - Difratograma de amostra sob a condição de cura $\mathrm{T}_{3}$ (carbonatação aos 27 dias) 


\begin{tabular}{c|c|r|r|r}
\hline & $\mathbf{T}_{\mathbf{0}}$ & \multicolumn{1}{c|}{$\mathbf{T}_{\mathbf{1}}$} & \multicolumn{1}{c}{$\mathbf{T}_{\mathbf{2}}$} & \multicolumn{1}{c}{$\mathbf{T}_{\mathbf{3}}$} \\
\hline Portlandita & 4.586 & 1.634 & 456 & 861 \\
\hline Calcita e silicatos & 7.513 & 12.780 & 12.834 & 12.728 \\
\hline
\end{tabular}

Tabela 5 - Intensidade dos picos (cps) referentes aos produtos de hidratação do cimento, obtidos por DRX

A partir da análise dos difratogramas e observação da Tabela 5, pode-se concluir que a amostra de compósitos submetidos às condições $\mathrm{T}_{0}$, ou seja, não carbonatadas, apresentou maior intensidade de pico relacionado à existência de portlandita $\left(\mathrm{Ca}(\mathrm{OH})_{2}\right)$. A amostra sob condição $\mathrm{T}_{2}$ não apresentou pico representativo para a portlandita, e as outras amostras $\left(\begin{array}{llll}\mathrm{T}_{1} & \mathrm{e} & \mathrm{T}_{3}\end{array}\right)$ apresentaram difratogramas com menores intensidades para essa fase cimentícia. Todas as amostras carbonatadas $\left(\mathrm{T}_{1}, \quad \mathrm{~T}_{2}\right.$ e $\left.\mathrm{T}_{3}\right)$ apresentaram pico com alta intensidade para a calcita $\left(\mathrm{CaCO}_{3}\right)$ e silicatos, se comparadas com a amostra não carbonatada $\left(\mathrm{T}_{0}\right)$. A melhora da interface entre fibra e matriz com maior formação $\mathrm{CaCO}_{3}$ e redução da quantidade de $\mathrm{Ca}(\mathrm{OH})_{2}$ justificam a melhora das propriedades mecânicas das amostras carbonatadas.

\section{Conclusões}

Neste trabalho foi mostrado que a carbonatação acelerada em idades iniciais de hidratação, após 2 dias de cura em câmara climática sob condições controladas, melhorou as propriedades mecânicas dos compósitos cimentícios com altos teores de polpas celulósicas. A carbonatação foi comprovada pela diminuição da intensidade dos picos de portlandita e aumento da intensidade de pico para a calcita, identificados por DRX. Essa condição de carbonatação resultou na densificação da matriz cimentícia e melhora na aderência entre fibra e matriz, conforme visualizado por microscopia eletrônica de varredura. Os resultados de resistência mecânica das amostras não carbonatadas foram inferiores às amostras carbonatadas devido ao alto teor de hidróxido de cálcio e à notável perda de aderência entre fibra e matriz cimentícia, o que proporcionou maiores valores de flecha específica e energia específica.

\section{Referências}

AGOPYAN, V.; SAVASTANO JUNIOR, H. Uso de materiais alternativos à base de fibras vegetais na construção civil: experiência brasileira. In: SEMINÁRIO IBEROAMERICANO DE MATERIALES FIBRORREFORZADOS, 1.; REUNIÓN PROYECTO PIP, 8., Cali. Anais... Cali: Universidad del Valle, 1997. p. 23-40.
AKERS, S. A. S; STUDINKA, J. B. Ageing Behaviour of Cellulose Fibre Cement Composites In Natural Weathering and Accelerated Tests. The International Journal of Cement Composites and Lightweight Concrete, v. 11, n. 2, p. 93-97, 1989.

\section{AMERICAN SOCIETY FOR TESTING AND} MATERIALS. ASTM C 948-81: test method for dry and wet bulk density, water absorption, and apparent porosity of thin sections of glass-fiber reinforced concrete. West Conshohocken, PA, 1981.

\section{AMERICAN SOCIETY FOR TESTING AND \\ MATERIALS. ASTM C150: standard \\ specification for Portland cement. West Conshohocken, PA, 2009.}

\section{ASSOCIAÇÃO BRASILEIRA DE NORMAS} TÉCNICAS. NBR 5733: cimento Portland de alta resistência inicial. Rio de Janeiro, 1991.

BENTUR A.; AKERS S. A. S. The Microstructure and Ageing of Cellulose Fibre Reinforced Autoclaved Cement Composites. International Journal of Cement Composites and Lightweight Concrete, v. 11, n. 2, p. 111-115, 1989.

BENTUR, A.; MINDESS, S. Fibre Reinforced Cementitious Composites. $2^{\text {nd }}$ ed. London: Taylor \& Francis, 2007.

BERGER, R. L.; KLEMM, W. A. Accelerated Curing of Cementitious Systems by Carbon Dioxide: accelerated curing of cementitious systems by carbon dioxide, part II, hydraulic calcium silicates and aluminates. Cement and Concrete Research. v. 2, p. 647-652, 1972.

BERTOS, M. F. et al. A Review of Accelerated Carbonation Technology in the Treatment of Cement-Based Materials and Sequestration of $\mathrm{CO}_{2}$. Journal of Hazardous Materials, v. B112, p. 193-205, 2004.

BEZERRA, E. M. et al. The Effect of Different Mineral Additions and Synthetic Fiber Contents on Properties of Cement Based Composites. Cement and Concrete Composites, v. 28, n. 6, p. 555-563, 2006. 
CALDAS E SILVA, A.; SAVASTANO JUNIOR, H.; JOHN, V. M. Envelhecimento de Compósitos à Base de Escória de Alto-Forno Reforçados com Polpa Celulósica Residual de Eucalipto. Ambiente Construído, Porto Alegre, v. 9, n. 1, p. 25-44, jan./mar. 2009.

COUTTS, R.S.P.; NI, Y. Autoclaved Bamboo Pulp Fibre Reinforced Cement. Cement and Concrete Composites, v. 17, p. 99-106. 1995.

GABRISOVA, A.; HAVLICA, J.; SAHU, S. Stability of calcium sulphoaluminates in water solutions with various $\mathrm{pH}$ values, Cement and Concrete Research, v. 21, n. 6, p. 1023-1027, 1991.

KLEMM, W. A.; BERGER, R. L. Accelerated Curing of Cementitious Systems by Carbon Dioxide: part I, Portland cement. Cement and Concrete Research, v. 2, n. 5, p. 567-576, 1972.

LAGERBLAD, B. Carbon Dioxide Uptake During Concrete Life Cycle: state of the art. Oslo: Swedish Cement and Concrete Research Institute, 2005.

MACVICAR, R.; MATUANA, L. M.; BALATINECZ, J. J. Aging Mechanism in Cellulose Fiber Reinforced Cement Composites. Cement and Concrete Composites, v. 21, n. 3, p. 189-196, 1999.

MOHR, B. J.; BIERNACKI, J. J.; KURTIS, K. E. Supplementary Cementitious Materials for Mitigating Degradation of Kraft Pulp FiberCement Composites. Cement and Concrete Research, v. 37, n. 11, p. 1531-1543, 2007.

PADE, C.; GUIMARÃES, M. The $\mathrm{CO}_{2}$ Uptake of Concrete in a 100 Year Perspective. Cement and Concrete Research, v. 37, n. 9, p. 1348-1356, set. 2007.

PETER, M. A. et al. Competition of Several Carbonation Reactions in Concrete: a parametric study. Cement and Concrete Research, v. 38, n. 12, p. 1385-1393, 2008.

SAVASTANO JUNIOR., H.; DANTAS, F. A. Z.; AGOPYAN, V. Materiais Reforçados com Fibras: correlação entre a zona de transição fibra-matriz e as propriedades mecânicas. São Paulo: IPT/Pini, 1994. 56 p. (Boletim 67)
SAVASTANO JUNIOR, H. Sistema de Cobertura para Construção de Baixo Custo: uso de fibras vegetais e de outros resíduos agroindustriais. 2000. $144 \mathrm{f}$. Tese (LivreDocência) - Escola Politécnica, Universidade de São Paulo, São Paulo, 2000.

SAVASTANO JUNIOR, H.; WARDEN, P. G.; COUTTS, R. S. P. Microstructure and Mechanical Properties of Waste Fibre-Cement Composites. Cement and Concrete Composites, v. 27, n. 5, p. 583-592, 2005.

SAVASTANO JUNIOR. H.; WARDEN, P. G.; COUTTS, R. S. P. Potential of Alternative Fibre Cements as Building Materials for Developing Areas. Cement and Concrete Composites, v. 25, n. 6, p. 585-592, 2003.

TAYLOR, H. F. W. Cement Chemistry. 2. ed. London: Thomas Telford Publishing, 1997.

TONOLI, G. H. D. et al. Effect of Fibre Morphology on Flocculation of Fibre-Cement Suspensions. Cement and Concrete Research, v. 39, n. 11, p. 1017-1022, 2009.

TONOLI G. H. D. et al. Refinement of Sisal Pulp: effect on the mechanical performance and durability of cement based composites. Materials and Manufacturing Processes, v. 22, n. 2, p. 149156, 2007.

TONOLI, G. H. D. et al. Effect of Accelerated Carbonation on Cementitious Roofing Tiles Reinforced With Lignocellulosic Fibre.

Construction and Building Materials, v. 24, n. 2, p. 193-201, fev. 2010a.

TONOLI, G. H. D.; et al. Eucalyptus Pulp Fibres as Alternative Reinforcement to Engineered Cement Based Composites. Industrial Crops and Products, v. 31, n. 2, p. 225-232, mar. 2010b.

\section{Agradecimentos}

À Fundação de Amparo à Pesquisa do Estado de São Paulo, pelo suporte financeiro ao desenvolvimento da pesquisa. 